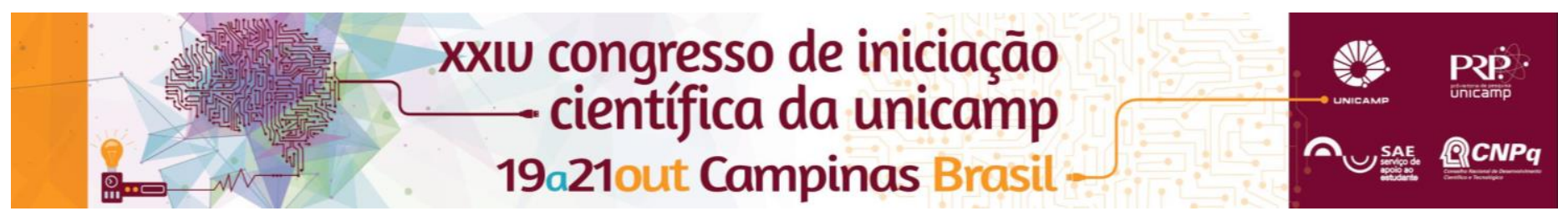

\title{
Aplicação de Métodos Numéricos de Alta Resolução Para a Solução de Escoamentos Compressíveis com Interação Choque-Turbulência
}

\author{
Brener L. O. Ramos*, William R. Wolf
}

\section{Resumo}

Métodos numéricos compactos que fazem uso de uma viscosidade artificial e métodos designados para captura de choque mesclados com interpolações WENO foram implementados e aplicados em problemas de escoamentos compressíveis. Tais problemas envolvem tanto gradientes elevados de propriedades, apresentados na forma de ondas de choque e superfícies de contato, quanto em estruturas suaves com diversas escalas espaciais e de frequência, comuns em escoamentos turbulentos.

\section{Palavras-chave:}

interação choque-turbulência, weno, hiperviscosity

\section{Introdução}

Escoamentos compressíveis de alta velocidade apresentam gradientes elevados de propriedades que surgem na forma de ondas de choque e superfícies de contato. Ao mesmo tempo, esses escoamentos são usualmente turbulentos e, portanto, ocorre a interação entre estruturas turbulentas e ondas de choque. Esse problema é comum em problemas de camadas-limite supersônicas que se desenvolvem sobre asas de aeronaves ou em bocais de foguetes.

Dessa maneira, o presente projeto de pesquisa aborda o estudo de métodos numéricos de alta resolução e suas aplicações em problemas que representam os mecanismos físicos descritos anteriormente. As equações de Euler, as quais representam conservação de massa, quantidade de movimento e energia, foram resolvidas com condições iniciais e de contorno representativas de problemas com interação choqueturbulência. Os métodos numéricos implementados foram um método compacto com viscosidade artifical $\left(\mathrm{O}\left(\Delta \mathrm{x}^{10}\right)\right)$ e um método de separação de diferenças de fluxos de Roe com uma interpolação WENO $\left(O\left(\Delta x^{5}\right)\right)$, todos a partir de diferenças finitas. A marcha no tempo foi realizada com um esquema Runge-Kutta TVD de terceira ordem.

\section{Resultados e Discussão}

Abaixo se encontram as soluções para o tubo de choque de Sod. É posível perceber que o método Compacto não captura tão bem a região no final da zona de expansão nem a superfície de contato. Já o choque é bem capturado por ambos os métodos.

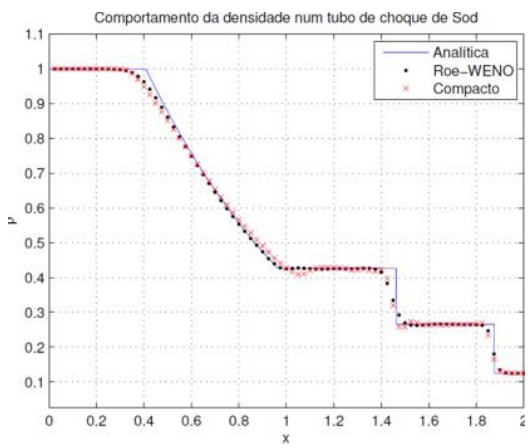

Figura 1: Resultados para o tubo de choque de Sod.

Já para o problema de Shu-Osher, os resultados foram semelhantes, com exceção que no método DOI: 10.19146/pibic-2016-50673
Compacto existe um "startup error" que contamina uma pequena parte da solução.

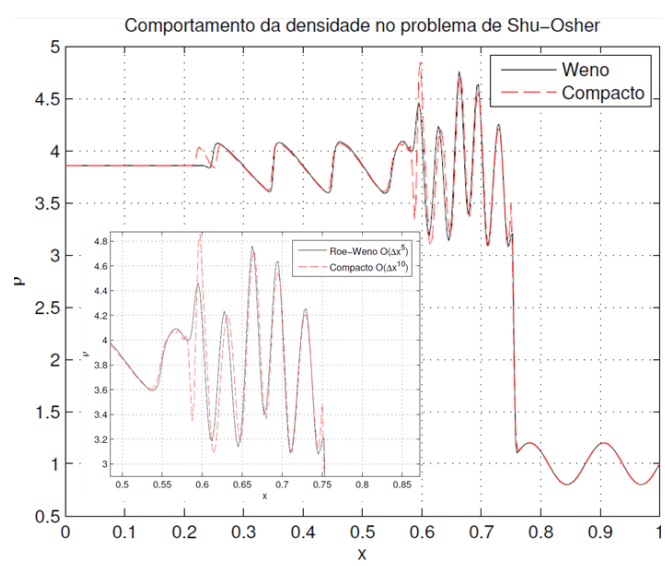

Figura 2. Resultados para o problema de Shu-Osher.

\section{Conclusões}

O método compacto com viscosidade artificial se mostrou mais barato computacionalmente, além de conseguir capturar oscilações em malhas menos refinadas devido a sua alta ordem. No entanto, em descontinuidades como superfícies de contato, é possível observar oscilações não-físicas. O mesmo ocorre numa pequena região para o problema de ShuOsher e ambos são causados pela falta de um termo dissipativo no fluxo da quantidade de movimento. Já o Roe-Weno se mostra um procedimento de custo computacional maior e apresenta bons resultados em todas as condições inicias usadas desde que houvesse um refinamento mínimo de malha. Além disso o critério de CFL para o método Compacto se mostrou mais sensível do que para o Roe-Weno.

\section{Agradecimentos}

Agradeço ao PIBIC pela bolsa concedida e ao meu orientador William. R. Wolf. Também agradeço ao suporte de todos do CFD Lab e da minha família.

\footnotetext{
${ }^{1}$ Cook, A. W.; Cabot, W. H., Hyperviscosity for shock-turbulence interactions, J. Comput. Phys. 2005, 203.

${ }^{2}$ S.K. Lele, Compact finite difference schemes with spectral-like resolution, J. Comput. Phys. 1992, 103.
}

3 Shu, C. W.; Osher, S. J., Efficient implementation of essentially nonoscillatory shock capturing schemes, J. comput. Phys. 1996, 126. 